\title{
WORKPLACE NOISE EXAMINATION IN A LABORATORY (CASE STUDY)
}

\author{
Dénes KOCSIS \\ University of Debrecen, Faculty of Engineering, Department of Environmental Engineering, Debrecen, Hungary, \\ kocsis.denes@eng.unideb.hu
}

\begin{abstract}
In this case study, the course and assessment of a work noise problem in a laboratory environment are described. Noise measurements are performed for the evaluation of workplace noise levels caused by the dominant sources at the site of the investigation. The results are evaluated according to the current Hungarian legislation, which is harmonized with the directives of the European Union. Based on the results noise protection interventions are shown to be required and proposals are described to solve the current situation.
\end{abstract}

Keywords: noise exposure, occupational noise, case study.

\section{Introduction}

It has long been known, that over-exposure to workplace noise may have adverse effects on human health. Over the past 40 years, numerous measures have been taken worldwide to reduce occupational noise. Different governments generally regulate the maximum noise exposure by workers in the second half of the 20th century [1], but there are exceptions, not just among third world countries [2]. Partly due to this, millions of people are still exposed to dangerous noise levels, which can cause irreversible health damage. In total the occupational noise exposure has decreased since the 1980s [3], but today it is still a major problem affecting many people.

In the case of workplace noise examination, the risk assessment is based on the protection of workers against the noise-related and presumably noise-originated factors that jeopardize the workers' health and personal safety. The risk assessment involves the identification of workers at risk as a result of noise exposure and the noise load they are subjected to. The practical purpose of the risk assessment is to determine the necessary measures where the worker's load reaches or exceeds the intervention limits [4]. In this context, the employers' obligations are set out in Arti- cle 4 of Directive 2003/10/EC of the European Parliament and of the Council of 6 February 2003 on the minimum health and safety requirements regarding the exposure of workers to the risks arising from physical agents (noise) [5], which states that "the employer shall assess and, if necessary, measure the levels of noise to which workers are exposed". Workers' responsibility is to assist in the noise measurements by sharing their knowledge of the working environment, the tools used and the specific tasks [6]. Furthermore, they must work together in the measurements by performing their work according to their daily working schedule, and thus the measurement results can adequately represent their true load.

In the present work the assessment and evaluation of the noise exposure are discussed in the form of a case study. The noise originates from the different sources of the laboratory and affects those who works or regularly stay there.

\section{Applied methods}

The site of the measurements was the Air and Noise Protection Laboratory of the Department of Environmental Engineering, Faculty of Engineering at the University of Debrecen. The laboratory was rebuilt in 2017 and a space has been separat- 
ed from the former undivided computing room for providing an environmental analytical test room. In this separated space, several analytical large instruments were placed and it became the scene for a PhD student's typical research work. In the area not covered by the separation, according to the previous practice, lessons are held during the study period on a daily basis.

\subsection{Dominant noise sources}

In among the analytical instruments placed inside the separated workspace is equipment working $24 / 7$ that causes a significant noise load, not only in the separated room, but also in the external study area. The problem was perceived and reported by teachers and students who had lessons there regularly. Before the start of the 2017/18 school year in September, the interior area was not airconditioned, but the overheating of the instruments was a potential source of danger, therefore the cooling of the separated room was solved by opening the doors and windows. This resulted in a significant increase in noise levels in the study room space. During summer, an air conditioner serving the interior area was implemented, so since then it has not been necessary to keep the doors and windows open for cooling purposes.

The major newly installed noise sources in the interior are as follows:

- Genius NM32LA nitrogen generator;

- Agilent 6140 Single Quadropole LC/MS System (liquid chromatography and mass spectrometer with a pre-vacuum pump);

- Agilent 1260 Infinity I ultrahigh pressure liquid chromatograph (UHPLC).

\subsection{The determination of workplace noise}

The measurements were performed using a Larson Davis Model 831 class 1 sound level meter. The noise measurements were carried out at a total of 7 measuring points, of which 3 were located within the separated area (Table 1.). The points were designated to be located within $50 \mathrm{~cm}$ of the head of the affected persons, although the persons were not present during the measurement. The location of the measuring points can be seen in Figure 1.
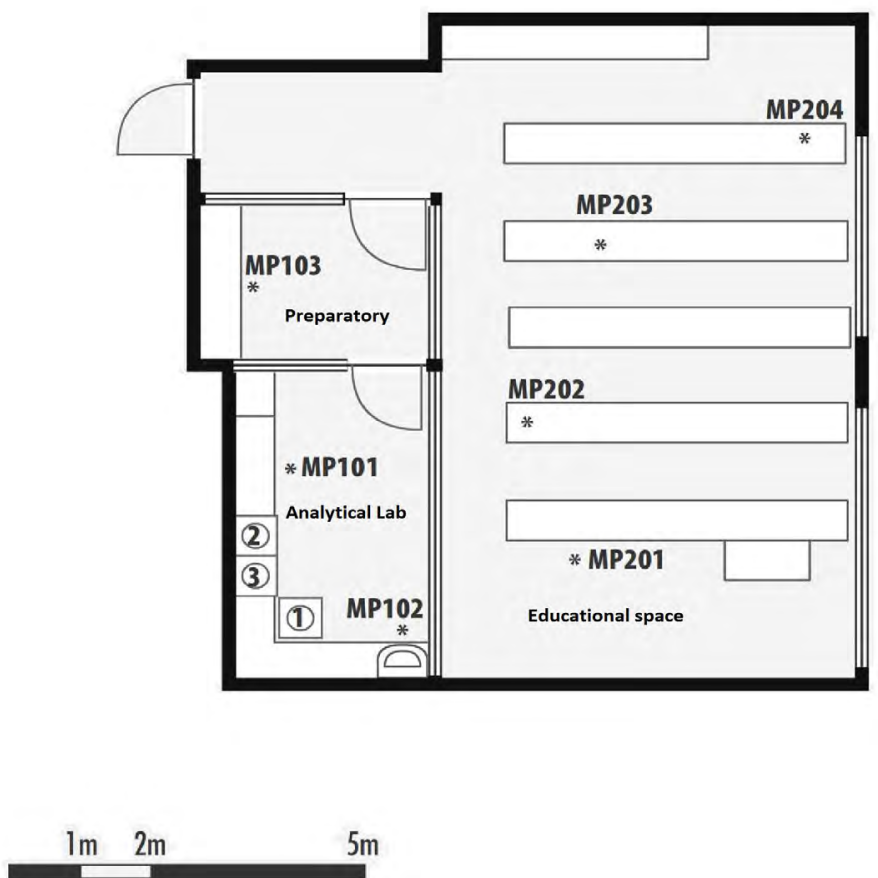

Figure 1. The location of the measuring points. Noise sources are numbered (1: Genius NM32LA, 2: Agilent 1260 UHPLC, 3: Agilent 6140 Single Quadropole LC / MS). The noise measuring points are marked with * (MP101 ... MP204) 
Table 1. The measuring points

\begin{tabular}{|c|c|c|c|}
\hline $\begin{array}{c}\text { Measuring } \\
\text { point }\end{array}$ & $\begin{array}{c}\text { Affected } \\
\text { persons }\end{array}$ & $\begin{array}{c}\text { Related activ- } \\
\text { ities }\end{array}$ & $\begin{array}{c}\text { Noise } \\
\text { character }\end{array}$ \\
\hline MP101 & \multirow{3}{*}{$\begin{array}{l}\text { PhD } \\
\text { student }\end{array}$} & $\begin{array}{c}\text { computerized } \\
\text { data processing, } \\
\text { evaluation }\end{array}$ & constant \\
\hline MP102 & & washing-up & constant \\
\hline MP103 & & preparation & constant \\
\hline MP201 & instructor & education & constant \\
\hline MP202 & \multirow{3}{*}{ students } & $\begin{array}{c}\text { participation in } \\
\text { education }\end{array}$ & constant \\
\hline MP203 & & $\begin{array}{l}\text { participation in } \\
\text { education }\end{array}$ & constant \\
\hline MP204 & & $\begin{array}{l}\text { participation in } \\
\text { education }\end{array}$ & constant \\
\hline
\end{tabular}

Given that the noise generated by the sources was found to be nearly constant, at each measurement point a 1 minute sampling measurement was performed and their adequacy was confirmed by the slight temporal fluctuations in the measurement results. The measurements were repeated three times under the same conditions.

\section{Results and evaluation}

The results at the measurement points are shown in Table 2. The results were evaluated on the basis of current Hungarian legislation. Legislation used in the evaluation:

- Decree No. 66/2005. (XII. 22.) EüM of the Minister of Health on the Minimum Health and Safety Requirements Regarding the Exposure of Workers from Noise (in accordance with Directive 2003/10/EC of the European Parliament and of the Council of 6 February 2003 on the minimum health and safety requirements regarding the exposure of workers to the risks arising from physical agents (noise))

- Decree No. 3/2002. (II. 8.) SzCsM-EüM of the Minister of Social Affairs and Family Affairs and the Minister of Health on the Minimum Work Safety Requirements of Workplaces

For the values in Table 2., it can be seen that $\mathrm{L}_{\text {cpeak }}$ values cannot cause problems because they are well below the limit (lower intervention limit: 135 dB (C) based on 2003/10/EC). The daily noise exposure results of the most affected PhD students were calculated for different daily activity intervals (including the current situation and potential future additional worktime increases) and the $\mathrm{L}_{\mathrm{EX}, 8 \mathrm{~h}}$ values were between 71 and $74 \mathrm{~dB}(\mathrm{~A})$.
Table 2. Measurement results (the highest LCpeak values and the average of LAeq values)

\begin{tabular}{|c|c|c|}
\hline $\begin{array}{c}\text { Measuring } \\
\text { point }\end{array}$ & $\mathbf{L}_{\text {cpeak }}[\mathbf{d B}(\mathbf{C})]$ & $\mathbf{L}_{\text {Aeq }}[\mathbf{d B}(\mathbf{A})]$ \\
\hline MP101 & 91.7 & 73.4 \\
\hline MP102 & 96.9 & 78.4 \\
\hline MP103 & 90.3 & 70.6 \\
\hline MP201 & 85.1 & 48.9 \\
\hline MP202 & 84.1 & 51.8 \\
\hline MP203 & 89.4 & 55.3 \\
\hline MP204 & 84.7 & 52.1 \\
\hline
\end{tabular}

Based on these, it can be stated that in none of the cases was the lower intervention limit value of $L_{E X, 8 \mathrm{~h}}=80 \mathrm{~dB}(\mathrm{~A})$ from 2003/10/EC exceeded (same limit value can be seen in Decree No. 66/2005).

According to Decree No. $3 / 2002$. (II. 8.) the $\mathrm{L}_{\text {Aeq }}$ value of the occupational noise shall not exceed $60 \mathrm{~dB}$ in case of analytical laboratories. Educational space as a separate category is not included in the decree, therefore a limit of $50 \mathrm{~dB}$ was applied (similarly to highly noise-sensitive office workplaces) to the exterior room. In our case study these limit values are typically exceeded by the measurement results.

\section{Conclusions}

Based on these results, noise protection interventions are required in order to improve the current situation in the examined laboratory. Reviewing the actions on the sources, actions of an organizational nature and actions on transmissions it can be stated that with purely organizational measures, the problem cannot be solved satisfactorily, yet there are organizational interventions that could be effective with other interventions. Among them the relocation of the evaluation activity combined with an action on transmissions can be highlighted, as it would be a solution to the whole area of the laboratory.

Moreover, the examination of the possibility of relocating the sources is also suggested. Some of the equipment in the interior part is typically located outside the analysed space, therefore this option also arises in this case. The relocation is expected to entail considerable expense, but it can be a longterm, secure solution.

Another solution is the enclosure of the dominant noise sources, where the spectral characteristics of the noise shall be taken into account. 
In the case of any of the drafted proposals, the PhD students and those in the outside area will not be affected by the unwanted, high exposure.

The publication is supported by the EFOP-3.6.116-2016-00022 project. The project is cofinanced by the European Union and the European Social Fund.

\section{References}

[1] Thurston F. E.: The worker's ear: A history of noise-induced hearing loss. American Journal of Industrial Medicine 56/3. (2013) 367-377. https://doi.org/10.1002/ajim.22095

[2] Arenas J. P., Suter A. H.: Comparison of occupational noise legislation in the Americas: an overview and analysis. Noise Health, 16/72. (2014) 306-319.

https://doi.org/10.4103/1463-1741.140511

[3] M. Sliwinska-Kowalska, Davis A.: Noise-induced hearing loss, Noise Heal 14/61. (2012) 274-280. https://doi.org/10.4103/1463-1741.104893
[4] European Commission: How to avoid or reduce the exposure of workers to noise at work - Nonbinding guide to good practice for the application of Directive 2003/10/EC, 2008.

[5] European Commission: Directive 2003/10/EC of 6 February 2003 on the minimum health and safety requirements regarding the exposure of workers to the risks arising from physical agents (noise), Off. J. Eur. Union, L 42/46. (2003) 38-44.

[6] Preventing occupational hearing loss: a practical guide (Eds.: Franks J. R., Stephenson M. R., Merry C. J.). DHHS (NIOSH) Publication No. 96-110. US Dept. of Health and Human Services, Public Health Service, Centers for Disease Control and Prevention, National Institute for Occupational Safety and Health, Division of Biomedical and Behavioral Science, Physical Agents Effects Branch, 1996. 